\title{
Study on the Effect of Process Approach in College English Writing Teaching
}

\author{
Sha $\mathrm{Li}^{1, \mathrm{a}}$ \\ ${ }^{1}$ Xi'an University of Technology, Xi'an, Shaanxi, 710048 \\ ${ }^{a}$ email
}

Keywords: Process Approach, College English Writing, Teaching Effect

\begin{abstract}
Writing has a very important role in college English teaching, as a part of language output, write enable learners to achieve the purpose of not only the language, but also the best indicator of the level of language learners. Traditional college English writing teaching method is always teacher-centered, often takes "proposition Teachers - Student Writing-Teacher marking" mode, the whole process, students can not get effective guidance of teachers and evaluation is not a valid student feedback. In the English curriculum reform, but there is a lot of English teachers for teaching writing confused, they need to lead theory to improve the effectiveness of writing course, you need to contact and learn from newer writing research. After explaining the history and status of development of teaching methods, teaching practice on the basis of its analysis of the strengths and weaknesses of development, this study will explore how the process approach used in English writing class to explore the feedback and evaluation process Approach an important role in the implementation process, and to improve students' English writing ability, promote the reform of college English writing teaching.
\end{abstract}

\section{Introduction}

Traditional writing teaching (product-focused approach) still dominates in the class. Under the guidance of the method in the classroom, the teacher is always in the leading position, and regards imparting knowledge and skills in writing as even the major activities. Therefore, when teachers are training students 'writing skills and abilities, they usually focus on guiding students to results of observation and thinking, ignoring how to train and develop students' thinking abilities. Throughout the writing process is completed by the teacher's domination and students have no chance to have a brainstorming. So writing becomes the output of the machinery. This teaching method may cause the results that students only write for finishing teachers' tasks and give more attention to writing form not the contents. Written work is artificial, empty and dull. in addition, most writings are out of reality, without taking into account of communicative needs of the students as the main body, which results in the loss of interest and confidence in writing. Most important, students lack a lot of language input and effective writing strategies, which makes them difficult in writing. Thus, writing becomes not only coping with the task of writing, but also has a severe effect on the development and improvement of students' creative thinking and writing skills.

\section{Traditional Writing Teaching Methods and Its Problems}

Product approach (the product approach) as a traditional writing teaching method has been very popular in our country, especially in the tight class, teaching content and more college English classroom teaching, writing as an element of the exercises in each unit, the general the approach is to teach the teachers after the completion of the unit content reserved for homework, by the concurrent further student teacher reviewers. This teaching method focusing on writing the final outcome of that is writing itself, should require students essay: "(1) meet the specified requirements for style; (2) to reflect the correct syntax student applications; (3) to the reader (teachers) think Specification organized. Therefore, teachers are from the content, organization, vocabulary, grammar, spelling, punctuation and other aspects to be evaluated on the student's essay. Students throughout the writing process is completed in a passive teacher dominated teachers reviewers and 
too much emphasis on language form, the result is often the teachers spent a lot of time and energy correcting serious writing, and students get concerned only after writing reviews and final score of teachers, writing for teachers and students have become a burden, can not achieve the purpose of teaching the syllabus requirements.

On the outcome of the Guidance Teaching writing classes, students' writing content, forms are under the strict control of teachers, many teachers and even to provide students with a fixed pattern (essay) requires students to write sets. However, due to the lack of student interest in the topic or content of teachers and teachers' provisions have different views on the subjective will have some resentment, often writing, simply to cope with trouble; although there are some students on subjective I would like to earnestly fulfill the task of writing, but because of the limitations of personal skills and English proficiency, write an essay unsatisfactory in all respects, over time, they lost interest in writing. All these reasons have led to the same result: the lack of student motivation and interest in writing, in the face writing task, did not know what to write, do not know how to write, sit in a daze after a rush completed. Resulting in a large number of students for the completion of writing exercises, teachers struggling marking stylized cycle.

\section{Process Teaching Approach}

Process Approach began in the 1970s, is to focus on the teaching of writing the writing process, concerns a method of teaching language skills of learners, the process of the writing process as a psychological process, thought process and the process of social communication, learner-centered protagonist, while mentors and teachers play the role of monitor, through student exchange interaction, life and discuss cooperation to improve writing skills of learners, the process of obtaining a good writing finished. The essence of the process approach is true of language teaching, classroom socialization to writing as a process. The basic performance characteristics: try to show knowledge, development of processes and scenarios, so that students have the cognitive impulse in this context, to stimulate the internal motivation to explore knowledge; moderately reproducing human cognitive processes, penetration and knowledge about the way of thinking; focus on exposure and research students' thinking process; appropriate to defer rendering issues conclusions.

Process Approach features five aspects: first, the process of writing a student-centered, teacher's role into mentors, supervisors and participants. Traditional teaching English writing, the central status of teachers throughout the writing process, teachers set the topic, the students writing, the final evaluation results are given scores, students always in a passive acceptance of the position of writing, writing enthusiastic. But in the process approach, the role of teachers face more diverse, more important tasks undertaken by teachers to the students the process of writing problems and timely feedback to guide students to revise and improve, supervise students' writing activities, and teachers have also actively students to participate in the discussion cooperation and work together to identify problems, analyze and solve problems, and finally the role of teachers to score student writing give an objective evaluation of actively helping students to correct errors appearing in the writing, creating good excellent works.

The introduction of feedback and evaluation has a number of changes. Compared with the traditional teaching writing, students finished writing one-off terminal feedback, feedback not only from the purpose of the process approach teachers, and classmates. Peer discussion analysis, find errors and shortcomings, to identify the advantages and strengths, life and peer assessment feedback. Expression of the subject matter in English effectively improve the level of writing, teacher feedback on student work evaluation, to guide the identity of coaching students to write effectively, thereby improving the efficiency of writing.

Teachers in the traditional teaching of writing correct spelling evaluation focused on grammar, correct use, if appropriate expression of words, the law requires teachers in the teaching process of writing both the content and structure of the language and correct knowledge at the same time, the content of the writing of whether prominent clear framework is clear and distinct to give advice and guidance, not a score based on how many students errors but in whether students meet the subject requirements, to achieve the purpose of teaching writing as a yardstick. 
Teachers and students, life and strengthen the interaction between the students enthusiasm high. Teacher feedback reflected a process of pedagogy teachers and students, positive interaction between life and life. Beneficial relationship between teacher and student exchanges between students and teachers is more intimate, reducing students' writing anxiety, enhance teacher-student emotion. In addition, the group also discussed cooperation between the students to understand each other and help each other and progress together and learning more relaxed and harmonious atmosphere, the enthusiasm of the students' writing can maximize it.

\section{Advantages and Scientific Character of Process Approach}

The process approach emphasizes learning through the writing process of writing, students focus on mining and expression of ideological content in a specific process of writing, and a series of activities by the specific operation, more fit the actual level of the students and cognitive rules, helping to train and stimulate student interest, promote writing ability. The use of the process approach, especially in some group activities and teaching activities of teachers deliberately arranged so that students became interested in writing and ideas, no longer is not to write about, I do not know what to say. And, through the implementation of the teaching process, students develop a conception, drafting and evaluation of good writing habits. And the entire process, students are actively involved, active construction process, which will undoubtedly reduce their writing psychological anxiety, and enhance confidence.

Process Approach is a teaching method in communication theory, the theory of cooperative learning effects. This pattern reflects the student-centered thinking, attention between teachers and students communicate using group activities and peer response, etc., to promote cooperation and exchanges between students, which is consistent with the concept of modern teaching. In this mode of teaching, the teacher's role is exemplary supporter, motivation, inspiration, guidance and evaluation, classroom activities organizer and guide, rather than a "mouthpiece", "chalk and talk" teacher-centered model, students are no longer afraid of the teacher, fear of writing, but writing activities into pleasant, positive experience writing process. The process of writing some meaningful activities, but also actively encourage students to explore learning, their initiative and creative thinking have been developed, and will help create a relaxed and harmonious learning atmosphere.

The present mode of writing is seen as social communication activities, pay attention to the purpose and intent of writing, writing emphasis on thinking, strategy development. Throughout the writing process student ability to think, which will train them to identify problems, analyze and solve problems, and to develop writing ideas, writing more real, more persuasive.

Writing evaluation only to pay attention to students 'language knowledge and language skills to master, but also pay attention to students' comprehensive ability to use language, taking into account the attitudes of students in the learning process and participation in performance. Evaluation of the body can be teachers, students, parents and the community. Teacher evaluation can be divided into the following categories: First, assess the overall performance of the whole class, noted that learning the advantages and problems, clear trends group learning activities. Third, the study group was evaluated. The fourth is to evaluate individual students. Student Assessment may take the following forms: First, the self-assessment, that student's own learning process or effect description, evaluation and reflection. Second, peer review, that is, the students each other on the other side of the learning process or evaluate the effect. Third group peer assessment and that the study group as a unit of the group members learn to evaluate the effect. Fourth, co-evaluation groups, namely the class participation and cooperation comment. Writing Evaluation methods include testing, measurement, observation, investigation, activity records. Measurements include measuring attitudes, emotions measurement and knowledge of the language measure; observe the simultaneous acquisition of information in the teaching activities. Writing Assessment tools include checklists and rating scales teaching, comments and so on. Checklist which means teachers will be looking for his behavior in a list provided to students, and students according to their performance details outlined in the checklist; teaching rating scale is a numerical grade classroom behavior. 
Comments are evaluated for work. Writing review includes writing reviews, writing and teaching evaluation process evaluation of three factors. Composition evaluation can be evaluated from the article content and form. The spirit and content of the article entity is the core of the composition. Subject excellent article should be clearly focused, because all materials and details around it should expand. If an article is very insightful, it will have thought and creative spirit. Even in the form of expression is not perfect, it should also be sure the potential exists to help it solve formal problems. It becomes possible to a good article. Forms may be considered from the organization, style and technical details of the three areas. Logic and effect of one article investigated the strength of the organizational structure, including the beginning of the development of convergence, text, and other end of each paragraph and between them. Organization, the structure of the article, it helps to render the subject and content, the article gives a sense of the framework and direction to the various parts of the article together. Good article always natural convergence, structural integrity.

\section{References}

[1] Graham Stanley. Approaches to process writing, Barcelon: British Council. 2006.

[2] Hyland, K. Teaching and Researching Writing [M]. Foreign Language Teaching and Research Press. 2005.

[3] Horowitz. What Processors Actually Require: Academic Tasks for the ESL Classroom. TESOL Quarterly. 1986, 20/3:445-461.

[4] Horowitz, D. M. Process, not product: Less than meets the eye [J]. TESOL Quarterly, 1986(20):141-144.

[5] Jensen, J.M. what do we know about the writing of elementary school children [J]. Language Arts. 1993(70):290-294. 